\title{
Humanizing Design of Nursing Home Facilities
}

$$
\text { Deqing } \mathrm{Bu}^{1,} \text { a } \text {, Feng Mengjiao }{ }^{2, \mathrm{~b}} \text {, Zhang } \mathrm{Bo}^{3, \mathrm{c}}
$$

${ }^{1}$ College of Architecture and Civil Engineering, North China University of Technology, Beijing

${ }^{2}$ College of Architecture and Civil Engineering, North China University of Technology, Beijing

${ }^{3}$ College of Architecture and Civil Engineering, North China University of Technology, Beijing a609986823@qq.com, bpipifmj@126.com, 790397535@qq.com

Keywords: urban park, aging population, pension buildings, pension institution

Abstract. To figure out the needs of senior citizens and build up a good environment is the central issue. An aging population has become one of the most serious issues in today's society and the pension industry is gradually developing to meet the demand, starting from the perspective of a market economy. Many pension institutions are making industrialization their goal for pension service, which ignores the needs of senior citizens. Therefore the issue at hand is to figure out the needs of senior citizens and to build a good environment.

\section{Principles}

Resources and cost conservation are the basic principles. According to the announcement of the Housing Quality Evaluation Technical Standard established by the Ministry of Construction, the service life of housing projects of our country is 50 years, but most of them have a service life of less than 30 years, resulting in great waste. Although they are old-fashioned, the building structure can be refurbished and then put to use. Therefore it is important to save their original structure and make the most of the basic implements by with a simple face-lift. (see Fig. 1)
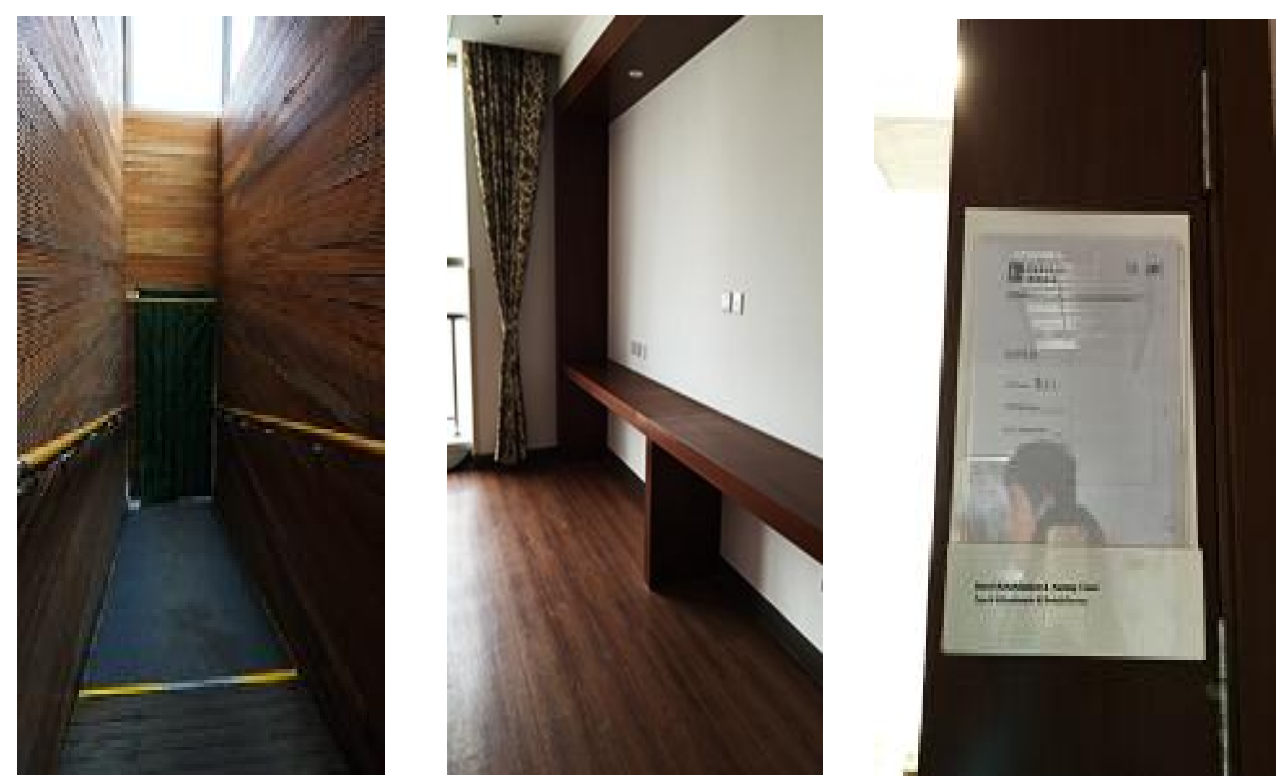

Fig. 1 Song Tang nursing house

Firstly, it's easy for senior citizens to become lonely and shut-in, therefore it's crucial to account for their psychological and behavioral needs; they want to communicate with others and be respected. Secondly, they have special behavioral characteristics such as slow movement and a lack of physical stamina, such as that needed to climb a flight of stairs. It is difficult for them to get around and many of them need wheelchairs. As a result, it is important to consider these specific needsduring the 
process of design and implementation. To do this, we need to adhere to the Barrier-free living standards and specifications

\section{Optimum Alzheimer Designing Strategies}

Spatial form. In times past, pension housing usually has a small area, and the living room and dining room are not very obvious in the housing design plan. From the perspective of housing that accommodates multiple generations, after accounting for things like storage space, the actual living area is quite small. In an effort to increase overall living area, we need to increase the area for the dining room, kitchen, and living room by combining them together. Some divisions are necessary however, like the division of public space and private space. If we combine the storeroom with the bedroom, it will definitely reduce the walking time and improve room usage rate. In this way we can design a layout which will benefit senior citizens. (see Fig.2)
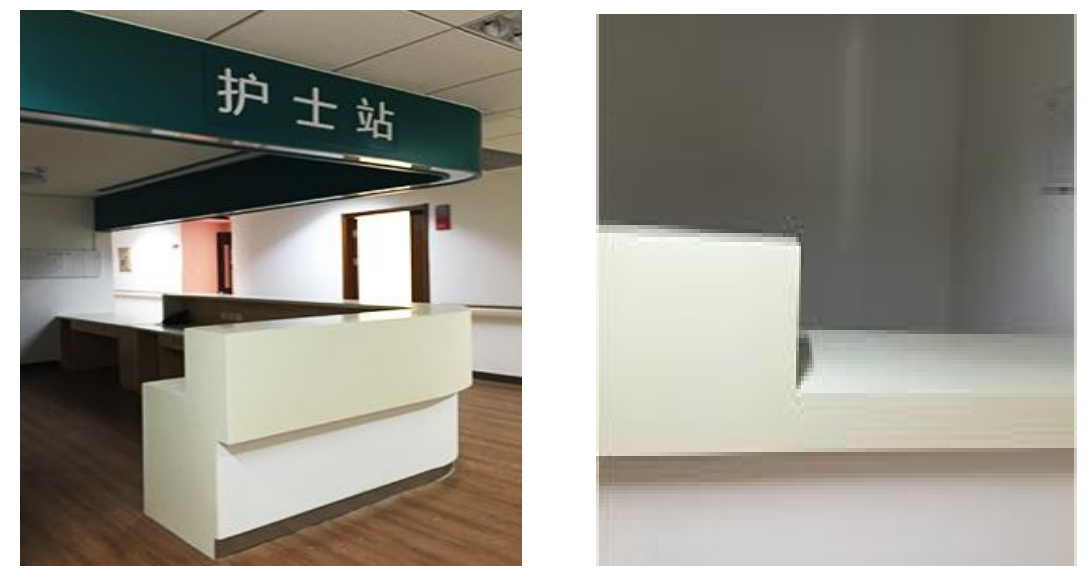

Fig. 2 Ying Zhi nursing house

Transportation transformation. It concerns the senior citizens greatly whether transportation is convenient. For those using wheelchairs, it is very inconvenient to come in and out without the ramp design. Barrier free design is the basic principle for pension buildings. The followings are some advice for pension building transforms:

A. The ramp design at the entrance of unit, handrail $0.90 \mathrm{~m}$ and armrest $0.65 \mathrm{~m}$ with ramp breadth no less than $1.80 \mathrm{~m}$.

B. Armrest of $0.65 \mathrm{~m}$ in the stairs, which is made of fine timber or other materials that feel good. Clear width no less than $1.5 \mathrm{~m}$; anti-skid materials, with heterochrome footgrip less than $3 \mathrm{~mm}$ in height. The front part is no more than $10 \mathrm{~mm}$.

C. Elevators are necessary for buildings with more than 6 floors. We have to confirm the convenience of wheelchair and stretcher coming in and out. Safety grab bar $0.90 \mathrm{~m}$ high from the ground.

Living space reform:

A. The bathroom. As the increasing of age, senior citizens use the bathroom more often. The old fashioned buildings have small space and insecure facilities, which is far from the bedroom. We can increase the usage rate of bathroom with certain service facilities. Lavabo design for wheelchair users. Wall cupboard in the kitchen design with a height of $1.40-1.50 \mathrm{~m}$. The depth of cupboard should be $0.25 \mathrm{~m}$ in advance of the counter top. The cupboard should no more high than $1.2 \mathrm{~m}$, and the operating floor should be $75 \mathrm{~cm}$ high.

Comfort design. The hall room and walking lobby should all use smooth wear-resisting temperature and moisture proof material, instead of stereoplasm smooth materials. Wood texture handrail with a radius of 3-4 cm, which suits a senior citizen's habits and physiological characteristics. The stairstep should be flat and barrier free, no back or any other deep colors. The floor of their living rooms should use stereoplasm or whippy plastic materials, no ceramic material. 


\section{Conclusion}

In order to achieve the goal of humanization design, we have to constantly solve the problems between senior citizens and buildings, care for their feelings and increase our humanization caring to a better level. But eventually, we should make them feel the love from our society and the beauty of life, which is the purpose of pension building design.

\section{Acknowledgements}

The project received undergraduate training - training model innovation pilot project - Training Excellence in Architecture (municipal) sponsored project number: PXM2014-014212-000015

\section{References}

[1] Wang Zhanfang, Hou Shuxiao, Peng Jialin. Beijing municipal pension services revenue investigations into the basic composing of the old man. China People Health Medical Science, 2004(4);19-24. (In Chinese)

[2] Beijing social welfare management division. Social Welfare Institutions. [EB/OL][2009-1] http://bjfl.bjmzj.gov.cn/index.do?websitId=900\&netTypeId=2. (In Chinese) 